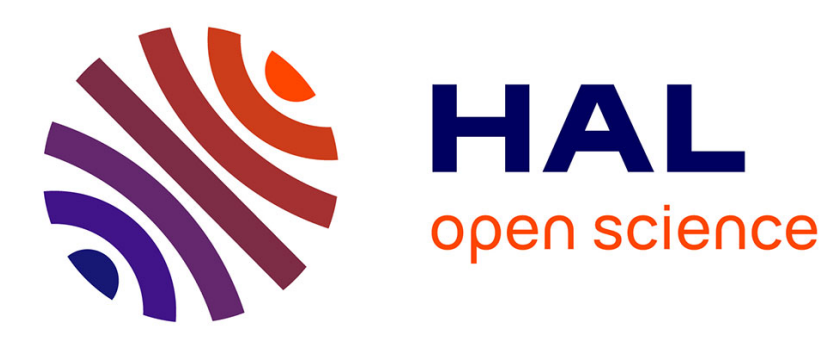

\title{
A Switchable Linear to Circular Polarization Converter Using PIN Diodes
}

\author{
Reda Madi, Antonio Clemente, Ronan Sauleau
}

\section{To cite this version:}

Reda Madi, Antonio Clemente, Ronan Sauleau. A Switchable Linear to Circular Polarization Converter Using PIN Diodes. 2021 International Symposium on Antennas and Propagation, Oct 2021, Taipei, Taiwan. hal-03515124

\section{HAL Id: hal-03515124 https://hal.science/hal-03515124}

Submitted on 6 Jan 2022

HAL is a multi-disciplinary open access archive for the deposit and dissemination of scientific research documents, whether they are published or not. The documents may come from teaching and research institutions in France or abroad, or from public or private research centers.
L'archive ouverte pluridisciplinaire HAL, est destinée au dépôt et à la diffusion de documents scientifiques de niveau recherche, publiés ou non, émanant des établissements d'enseignement et de recherche français ou étrangers, des laboratoires publics ou privés. 


\title{
A Switchable Linear to Circular Polarization Converter Using PIN Diodes
}

\author{
Reda Madi ${ }^{1}$, Antonio Clemente ${ }^{1 *}$, Ronan Sauleau ${ }^{2}$ \\ ${ }^{1}$ CEA-Leti, Université Grenoble Alpes, F-38000 Grenoble, France \\ ${ }^{2}$ Univ Rennes, CNRS, IETR (Institut d'Electronique et des Technologies du numéRique) - UMR CNRS 6164 \\ F-35000 Rennes, France \\ *antonio.clemente@cea.fr
}

\begin{abstract}
In this paper, we present a method to design a switchable polarizer using $p$-i-n diodes. An antenna-filterantenna architecture with four metal layers (receiving and transmitting radiating elements, ground plane, and bias lines) is implemented to convert an impinging linearly-polarized electromagnetic wave to a circularly-polarized one. Furthermore, by controlling opportunely the bias current flowing on the two pi-n diodes flip chipped on the transmitting radiating element, the transmission wave can be switched to either left-handed circular polarization (LHCP) or right-handed circular polarization (RHCP). Full-wave electromagnetic simulations of a single element show a transmission loss $<0.8 \mathrm{~dB}$ for both polarization (LHCP/RHCP) and $180^{\circ}$ phase difference in the frequency band (27 - 31 GHz).
\end{abstract}

Keywords - Polarizer, circular polarization, polarization converter, p-i-n diodes, EM-wave manipulation, mm-wave applications.

\section{INTRODUCTION}

Nowadays broadband satellite communications (SatCom) at $\mathrm{K}-/ \mathrm{Ka}$-band are experiencing a growing interest. In this applicative context, one of the most important antenna requirement is the capability to radiate a circularly-polarized beam. Indeed, circular polarization $(\mathrm{CP})$ is used to mitigate Faraday rotation effects, multi-path fading, and interferences caused by environmental factors, such as rain or fog. Furthermore, CP switch is also essential for terminal antennas to handle with the handover from one cell to another one.

$\mathrm{P}-\mathrm{i}-\mathrm{n}$ diodes based reconfigurable transmitarray antennas [1],[2], with electronic beam steering and CP agility, have been proposed recently as an energy-efficient alternative to classical phased arrays. In order to simplify the antenna architecture and limit the number of switches, these transmitarrays use a random distribution of vertical and horizontal polarized unit-cells to generate the CP. Even if this strategy allows to achieve extremely low axial ratio $(<1 \mathrm{~dB})$, a gain reduction of $3 \mathrm{~dB}$ is obtained due to the particular sequential rotation schemes used to generate $\mathrm{CP}$. An alternative solution to generate $\mathrm{CP}$ agility without sequential rotation losses is the combination of a linearly-polarized antenna with a switchable linear-to-circular polarization converter. Several passive [3]-[5] and reconfigurable [6],[7]Error! Reference source not found. polarization converters have been proposed in the literature.

In this contribution, a reconfigurable linear-to-circular polarization converter is proposed. Compared to the state of the art, the proposed architecture uses only two p-i-n diodes and a single bias line to generate the polarization switch.

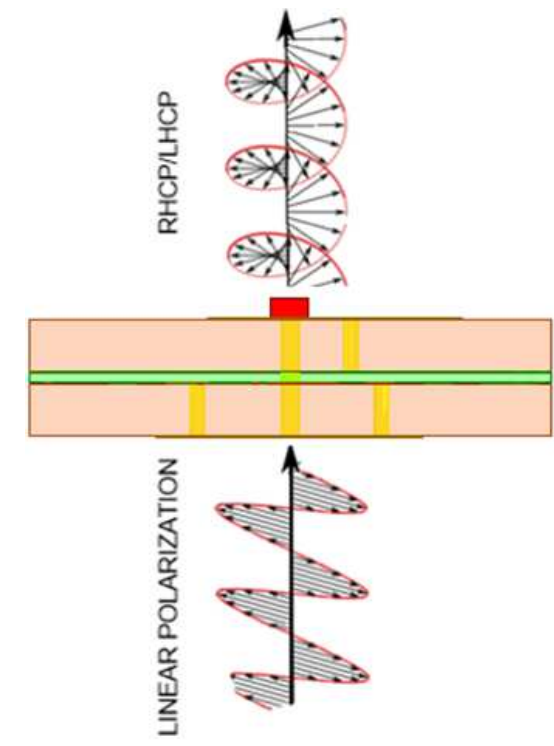

(a)

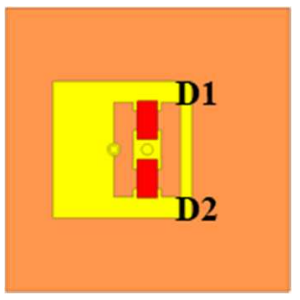

(b)

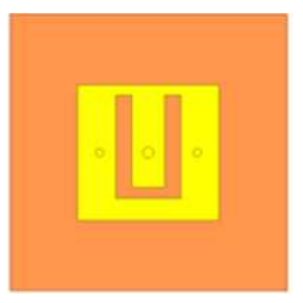

(c)
Fig. 1. Circular polarizer unit-cell (a) side view, (b) top view and (c) bottom view.

\section{UNIT-CELL DESIGN}

The unit-cell of the proposed polarization converter operates at Ka-band $(27-31 \mathrm{GHz})$. Its aperture size equals $5.1 \times 5.1 \mathrm{~mm}^{2}$ (i.e. $\lambda_{0} / 2 \times \lambda_{0} / 2$, where $\lambda_{0}$ is the wavelength in free space at $29.4 \mathrm{GHz}$ ). The selected stack-up is shown in Fig. 1(a). It consists of two identical substrates (Astra MT77, thickness $508 \mu \mathrm{m}, \varepsilon_{r}=3$ and $\tan \delta=0.0017$ ), a bonding film and four metal layers. The receiving $(R x)$ layer is composed of a linearly-polarized square patch loaded by a U-shaped slot (Fig. 1(c)). At the transmitting layer $(T x)$, an active patch loaded by an O-shaped slot and two p-i-n diodes (indicated as D1, D2 in Fig. 1(b)) is design. An asymmetric excitation is selected to generate $\mathrm{CP}$. The two patches are connected with a metallized via hole placed at the center of the unit-cell. A ground plane and the bias line are realized on the inner layers. Metallized vias are used to connect the $R x$ and the $T x$ patch antennas to the ground plane and the bias line, respectively.

As presented in Table I, the linear-to-circular polarizer converter operates in RHCP when D1 is ON and D2 is OFF. 
LHCP is achieved when D1 is OFF and D2 is ON in the frequency. The diodes states are controlled by using a negative or a positive current of $10 \mathrm{~mA}$.

\section{TABLE I TRUTH TABLE OF THE PROPOSED POLARIZATION CONVERTER}

\begin{tabular}{|c|c|c|}
\hline \multicolumn{2}{|c|}{ Diode state } & \multirow{2}{*}{ Polarization } \\
\hline D1 & D2 & RHCP \\
\hline ON & OFF & LHCP \\
\hline OFF & ON & \\
\hline
\end{tabular}

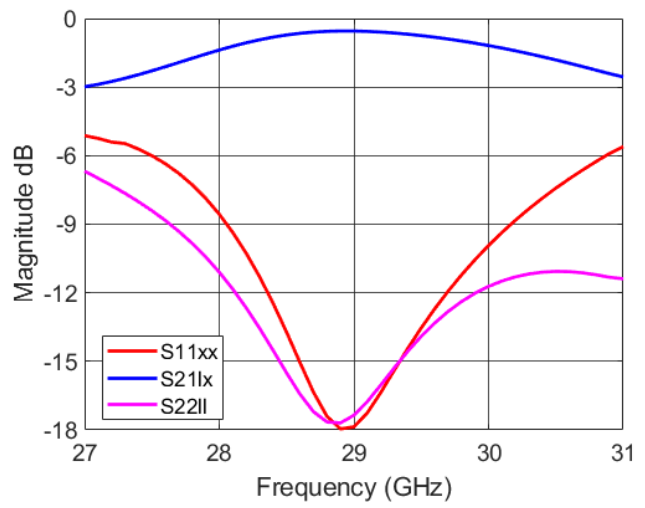

(a)

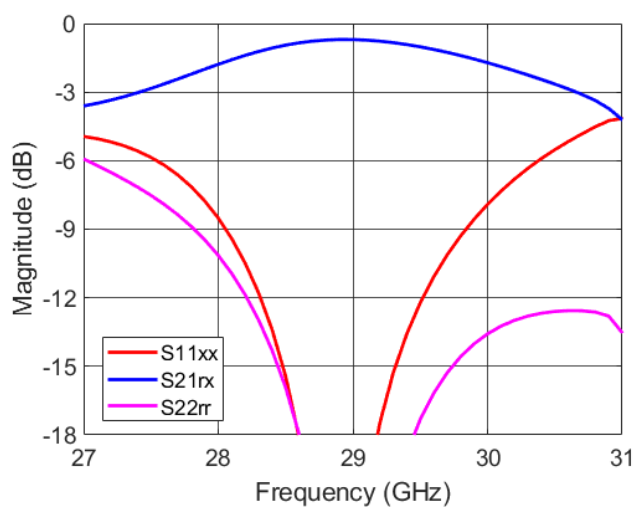

(b)

Fig. 2. Amplitude of the transmission and the reflection coefficients for the (a) LHCP and the (b) RHCP.

\section{SIMULATION RESULTS}

The proposed unit-cell has been simulated and optimized using the commercial software Ansys HFSS with periodic boundary conditions and Floquet port excitations. The $p-i-n$ diode are modeled as in [1],[2]. The simulated magnitude of the reflection and the transmission coefficients of the polarizer and the transmission phase are shown in Fig. 2 and Fig. 3, respectively. It is observed that by changing the state of the diode we can switch from left handed to right handed circular polarization, Figs. 2(a)-(b), respectively. Very similar results are obtained for the two states. At $29 \mathrm{GHz}$, the unit-cell exhibits a minimum insertion loss of 0.70 and $0.55 \mathrm{~dB}$ for the
LHCP and RHCP, respectively. The 3-dB relative transmission bandwidth is equal to $15.2 \%$ and $11.4 \%$ for the LHCP and the RHCP, respectively.

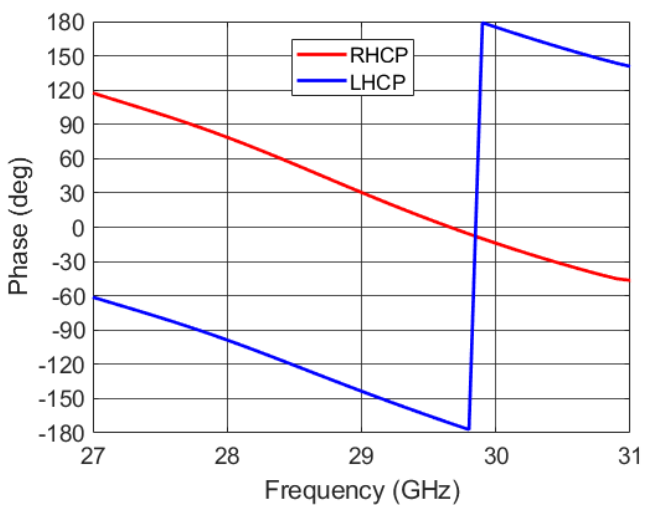

Fig. 3. Transmission phase for the RHCP and the LHCP.

\section{CONCLUSION}

In this paper, we presented a polarizer that converts a linearly polarized wave to a circularly polarized one. It operates at Ka-band and can be electronically switched to LHCP or RHCP by changing the states of the $\mathrm{p}-\mathrm{i}-\mathrm{n}$ diode. The proposed UC exhibits $15.17 \%$ and $11.38 \% 3-\mathrm{dB}$ transmission bandwidth at $29 \mathrm{GHz}$ for the LHCP and the RHCP, respectively.

\section{ACKNOWLEDGMENT}

This work was partly supported by the National Research Agency (ANR) through the project ANR-ASTRID ArtiKa under grant ANR-20-ASTR-0014-01.

\section{REFERENCES}

[1] L. Di Palma, A. Clemente, L. Dussopt, R. Sauleau, P. Potier, P. Pouliguen "Circularly-polarized reconfigurable transmitarray in Kaband with beam scanning and polarization switching capabilities," IEEE Trans. Antennas Propag, Vol 65, no. 2, pp 529-538, Feb. 2017.

[2] F. Foglia Manzillo, M. Smierzchalski, J. Reverdy, and A. Clemente, "A Ka-band beam-steering transmitarray achieving dual-circular polarization," in Proc. 15 th Eu. Conf. Antennas Propag. (EuCAP 2021), Dusseldorf, Germany, Mar. 2021.

[3] I. Sohail, Y. Ranga, K.P. Esselle, and S.G. Hay, "A linear to circular polarization converter based on Jerusalem-cross frequency selective surface," in Proc. $7^{\text {th }}$ Eu. Conf. Antennas Propag. (EuCAP), Gothenburg, Sweden, Apr. 2013.

[4] F. Foglia Manzillo, M. Ettorre, R. Sauleau, and A. Grbic, "Systematic design of a class of wideband circular polarizers using dispersion engineering," in Proc. 11th Eur. Conf. Antennas Propag. (EUCAP), Paris, France, Mar. 2017, pp. 1279-1281.

[5] M. Fartookzadeh and S. H. Mohseni Armaki, "Dual-band reflectiontype circular polarizers based on anisotropic impedance surfaces," IEEE Trans. Antennas Propag., vol. 64, no. 2, pp. 826-830, Feb. 2016.

[6] L. Wenting, G. Steven, C. Yuanming, L. Qi, S. Mohammed "Polarization-reconfigurable circularly polarized planar antenna using switchable polarizer," IEEE Trans. Antennas Propag., vol. 65, no. 9, pp. 4470-4477, Sep. 2017.

[7] Q. Jiang, J. Shen, C. Wang, X. Wu, and J. Zhou, "A switchable circular polarizer based on active metasurface at $30 \mathrm{GHz}$," in Proc. Int. Symp. Antennas Propag. (IEEE APS/URSI), Montreal, QC, Canada, Jul. 2020. 